\title{
Article \\ Microstructure/Mechanical Characterization of Plasma Nitrided Fine-Grain Austenitic Stainless Steels in Low Temperature
}

\author{
Abdelrahman Farghali ${ }^{1}\left(\mathbb{D}\right.$, Tatsuhiko Aizawa ${ }^{2, * \mathbb{D}}$ and Tomoaki Yoshino ${ }^{3}$ \\ 1 Mechanical Engineering Department, Faculty of Engineering, Suez Canal University, Ismailia 41522, Egypt; \\ abdelrahman_mohamed@eng.suez.edu.eg \\ 2 Surface Engineering Design Laboratory, Shibaura Institute of Technology, Tokyo 144-0045, Japan \\ 3 Komatsu-Seiki Kosakusho, Co., Ltd., Nagano 392-0022, Japan; yoshino@komatsuseiki.co.jp \\ * Correspondence: taizawa@sic.shibaura-it.ac.jp; Tel.: +81-3-6424-8615
}

Citation: Farghali, A.; Aizawa, T.; Yoshino, T. Microstructure/

Mechanical Characterization of

Plasma Nitrided Fine-Grain

Austenitic Stainless Steels in Low

Temperature. Nitrogen 2021, 2,

244-258. https://doi.org/10.3390/

nitrogen2020016

Academic Editor: Stephen Macko

Received: 3 March 2021

Accepted: 10 May 2021

Published: 13 May 2021

Publisher's Note: MDPI stays neutral with regard to jurisdictional claims in published maps and institutional affiliations.

Copyright: (c) 2021 by the authors. Licensee MDPI, Basel, Switzerland. This article is an open access article distributed under the terms and conditions of the Creative Commons Attribution (CC BY) license (https:/ / creativecommons.org/licenses/by/ $4.0 /)$.

\begin{abstract}
Fine-grained austenitic stainless steels (FGSS) were plasma nitrided below $700 \mathrm{~K}$ to describe their microstructure evolution during the nitrogen supersaturation process and to investigate the post-stressing effect on the microstructure and mechanical properties of nitrided FGSS. Normal- and fine-grained AISI304 plates were nitrided at $623 \mathrm{~K}$ and $673 \mathrm{~K}$ to investigate the grain size effect on the nitrogen supersaturation process as well as the microstructure evolution during the nitriding process. Fine-grained AISI316 (FGSS316) wires were nitrided at $623 \mathrm{~K}$ to demonstrate that their outer surfaces were uniformly nitrided to have the same two-phase, refined microstructure with high nitrogen solute content. This nitrided FGSS316 wire had a core structure where the original FGSS316 core matrix was bound by the nitrided FGSS316 layer. The nitrided wire had higher stiffness, ultimate strength, and elongation in the uniaxial tensile testing than its un-nitrided wires. The core microstructure was refined and homogenized by this applied loading together with an increase of nitrided layer hardness.
\end{abstract}

Keywords: fine-grained austenitic stainless steels; low-temperature plasma nitriding; strengthening; hardening; biomedical applications

\section{Introduction}

Austenitic stainless steels as well as titanium and titanium alloys have been utilized as biomedical components [1]. In particular, fine-grained austenitic stainless steel wire is highlighted as a new biomaterial tool to advance endoscopic surgical operations [2,3]. Owing to the high strength, hardness, and toughness of this wire, a larger load can be applied in cutting the tumors and in picking up the cells without causing wear or damage to organs in the human body during endoscope surgical operations [4]. Further improvement of strength and corrosion toughness in the fine-grained stainless steels has become an emergent demand from medical professionals [5]. After [6], there are many heat and surface treatments for strengthening and hardening of stainless steel. The formation of nitride, oxide, and carbide precipitates in these treatments is undesirable because of the significant modification to the original homogeneous microstructure to austenitic phase steels, as well as reduction of the erosion and corrosion toughness after surgical operations [7]. Stainless steel heat treatment above the onset of surface coloring around $700 \mathrm{~K}$ is prohibited as a medical wire product [8]. Ceramic coatings as well as carburizing and nitriding processes above $700 \mathrm{~K}$ are never employed as a candidate processing. As surveyed in [9], there have been many studies on the low-temperature plasma nitriding of austenitic stainless steels since nitrogen supersaturation was first found. In the literature on the nitrogen supersaturation of AISI304 stainless steels, most plasma nitriding processes were performed above $673 \mathrm{~K}$ for a longer time than $15 \mathrm{ks}$. As common results in those studies, the thin nitrided layer was formed to have a thickness less than $20 \mu \mathrm{m}$ by nitrogen supersaturation and diffusion to the depth of AISI304 specimens. The average hardness 
reached $1200 \mathrm{HV}$ by plasma nitriding at $673 \mathrm{~K}$ for four to eight hours. Few statements were found on the grain size effect on this nitrogen supersaturation and on the microstructure evolution during nitriding. As stressed in [10], this nitrogen supersaturation is the key to combining the benefits of a stable austenitic structure with higher strength, better corrosion, and wear resistance and superior biocompatibility in comparison to the currently used austenitic stainless steel, especially AISI316. After [11-15], precise analysis of the micro/nanostructure of nitrogen supersaturated AISI316 steels reveals that they have a two-phase nitrided layer with the grain size refined down to $0.1 \mu \mathrm{m}$. The nitrided layer thickness reaches $60 \mu \mathrm{m}$ even by the RF (radio frequency)—DC (direct current) high-density plasma nitriding at $673 \mathrm{~K}$. This in situ refinement of the crystalline structure of AISI316 steels is accompanied by homogeneous nitrogen supersaturation and diffusion deep in their matrix. This homogeneity in the inner nitriding process was enhanced by refining the initial grain size of austenitic stainless steels.

In the present paper, an AISI304 plate specimen is employed to investigate the role of initial grain size in the nitrogen supersaturation at 623 and $673 \mathrm{~K}$. The full-martensitic microstructure of intensely rolled AISI304 plates changes to a two-phase, fine-grained one in the nitrided layer with a thickness of $50 \mu \mathrm{m}$. SEM (Scanning Electron Microscopy) —EDS (Electron Dispersive spectroscopy), EBSD (Electron Back-Scattering Diffraction), and XRD (X-ray Diffraction) analyze the role of the initial grain size in the inner nitriding process. A two-step inner nitriding mechanism of the heterogeneous and homogeneous nitrogen supersaturation processes in the normal-grained AISI304 (NGSS304) changes to a singlestep homogeneous nitriding mechanism in the fine-grained AISI304 (FGSS304). Next, the fine-grained AISI316 (FGSS316) wire is plasma nitrided at $623 \mathrm{~K}$. This nitrided FGSS316 wire has a core structure bound by a uniform nitrided surface layer with high strength and hardness. This core-structured wire has higher ultimate strength and elongation than un-nitrided FGSS316 wire. Increased hardness and homogeneous microstructure evolution during the uniaxial loading reveals that the external plastic straining can promote the core-microstructure structure with the nitrided layer.

\section{Experimental Procedure}

\subsection{Hollow Cathode Device Design in the RF/DC Plasma Nitriding System}

The high-density RF-DC plasma nitriding system is depicted in Figure 1a. It consists of a vacuum chamber, evacuation system, gas supply, RF/DC-power generator, and control panel.

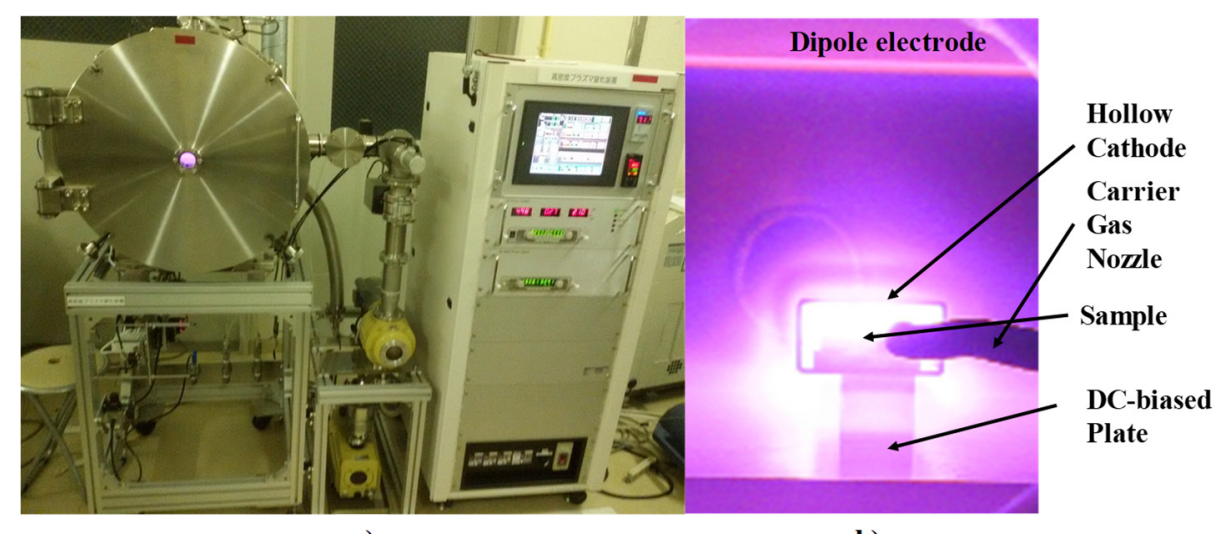

a)

b)

Figure 1. High-density low-temperature plasma nitriding system. (a) Overall configuration of nitriding system and (b) illustration on the hollow cathode device for high densification of nitrogen ions and NH-radicals.

Every processing parameter is specified and modified by this panel. The hollow cathode device was utilized to intensify the density of nitrogen ions as well as the $\mathrm{NH}$ radicals, as shown in Figure 1b. The plate specimen was located in this hollow for high- 
density plasma nitriding. This hollow device was redesigned for the plasma nitriding of wire specimens. As illustrated in Figure 2, the wire specimen was placed coaxially along the central axis of the hollow with its one end supported by the fixture. This fixture was electrically connected to the DC-bias.
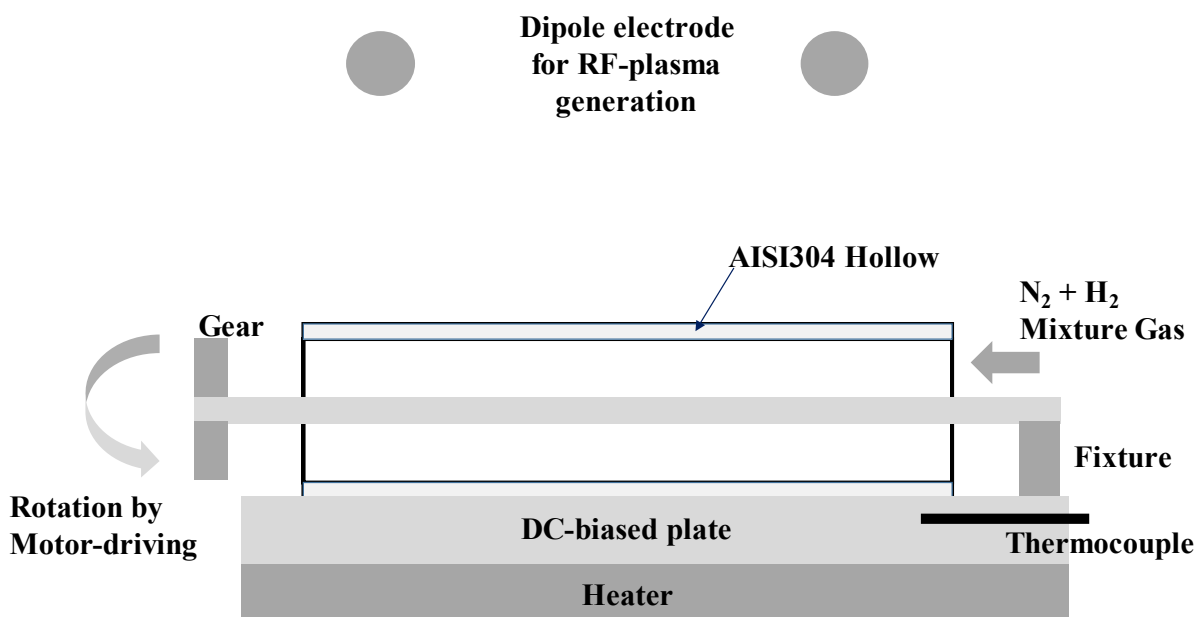

Figure 2. Experimental setup of FGSS316 wire in the hollow cathode for plasma nitriding at $623 \mathrm{~K}$.

The standard nitriding conditions are as follows: the holding temperature is 623 and $673 \mathrm{~K}$, the RF-voltage is $+250 \mathrm{~V}$, the DC bias is $-500 \mathrm{~V}$, the gas pressure is $70 \mathrm{~Pa}$, and the mixture gas flow rate is $160 \mathrm{~mL} / \mathrm{min}$ for nitrogen and $30 \mathrm{~mL} / \mathrm{min}$ for hydrogen, respectively. In the following experiments, the specimen was fixed into the hollow cathode device before evacuation down to the base pressure of $0.1 \mathrm{~Pa}$. The specimen was presputtered for $1.8 \mathrm{ks}$ at $70 \mathrm{~Pa}$ at each holding temperature under the nitrogen gas flow by a DC-bias of $-500 \mathrm{~V}$. After pre-sputtering, the nitriding process started and continued for $14.4 \mathrm{ks}$ at $70 \mathrm{~Pa}$ at $623 \mathrm{~K}$ and $673 \mathrm{~K}$. After nitriding, the specimen was cooled down under the nitrogen atmosphere in the chamber. In a similar manner, the FGSS316 wires were nitrided at $623 \mathrm{~K}$ for $14.4 \mathrm{ks}$ at $70 \mathrm{~Pa}$.

\subsection{Work Materials}

An NGSS304 plate was utilized as a test piece to describe the effect of grain size on the nitrogen supersaturation. An intense rolling process in cold was employed to prepare the fine-grained and textured AISI304 (FGSS304) specimen by high reduction of thickness from $10 \mathrm{~mm}$ to $1 \mathrm{~mm}$. FGSS316 wire with the average grain size of $1.7 \mu \mathrm{m}$ was prepared to demonstrate the strengthening process by low-temperature plasma nitriding. The chemical compositions of NGSS304, FGSS304, and FGSS316 were listed in Table 1, respectively.

Table 1. Chemical compositions of NGSS304, FGSS304, and FGSS316.

\begin{tabular}{ccccccccc}
\hline SS & C & Ni & Cr & Mn & Mo & Si & P & S \\
\hline $\begin{array}{c}\text { NGSS304 } \\
\text { FGSS304 }\end{array}$ & 0.07 & 8.54 & 18.45 & 2.00 & --- & 1.00 & 0.044 & 0.02 \\
\hline FGSS316 & 0.08 & 12.0 & 17.0 & 2.00 & 2.5 & 1.00 & $<0.045$ & $<0.030$ \\
\hline \multicolumn{7}{c}{ Balance in iron (Fe) } \\
\hline
\end{tabular}

\subsection{Analysis and Measurement}

NGSS304 and FGSS304 specimens before and after nitriding were analyzed by the X-ray diffractometer (XRD; Rigaku SmartLab, Tokyo, Japan) with monochromatic $\mathrm{CuK} \alpha$ radiation $(\lambda=0.1542 \mathrm{~nm})$ and Bragg-Brentano geometry, $40 \mathrm{kV}, 30 \mathrm{~mA}$. The $2 \theta$ range was set between $30^{\circ}$ to $90^{\circ}$ with the scanning speed of $10 \mathrm{~mm} / \mathrm{min}$ and the step angle of $0.02^{\circ}$. 
The microhardness testing apparatus (HM-200, Mitsutoyo; Yokohama, Japan) was used by applying the load of $50 \mathrm{~g}$ or $0.5 \mathrm{~N}$ for cross-section measurements every $10 \mu \mathrm{m}$, respectively. The matrix hardness of NGSS304 was $400 \mathrm{HV}$ while the rolled specimen reached $670 \mathrm{HV}$ by grain size refinement during the rolling.

SEM (SU-70, HITACHI, Tokyo, Japan) was used for microstructure observation. First, the specimen is attached to the specimen holder device and inserted into a high vacuum chamber. Then the electron beam was irradiated at the accelerating voltage of $5 \mathrm{KV}$ with a working distance from the analyzed surface of $15 \mathrm{~mm}$. The YAGBSE device was used for controlling the contrast as well as the focus and for adjusting the electron beam alignment to the area to be analyzed. An EDS device and software package were then utilized for element mapping over a specified depth for nitrogen, chromium, iron, and carbon. EBSD (Shimazu, Co., Ltd.; Kyoto, Japan) was utilized with an accelerating voltage of $20 \mathrm{kV}$, a working distance of $20 \mathrm{~mm}$, a $\times 2000$ magnification, and a resolution of $0.1 \mu \mathrm{m}$. The inverse pole figure (IPF) was determined for each constituent grain to describe the change in microstructure through the nitriding. In addition, the kernel average misorientation (KAM) and the phase mapping were also measured to explain the plastic straining and phase transformation processes, respectively.

The uniaxial tensile loading test was performed using the precision universal testing machine AUTOGRAPH AGS-X $10 \mathrm{kN}$ (Shimazu Co., Ltd., Kyoto, Japan). This uniaxial loading was terminated when the maximum applied load reached $6 \mathrm{kN}$ before fatal ductile fracture for microstructure analyses.

\section{Experimental Results}

The nitrogen supersaturation process in NGSS304 and FGSS304 plates is experimentally described by plasma nitriding at $673 \mathrm{~K}$ and $623 \mathrm{~K}$. The grain size effect on this nitrogen supersaturation is investigated by precise analysis of the microstructure evolution. FGSS316 wire is employed to demonstrate that a wire has a uniformly nitrided hard layer with a thickness of $40 \mu \mathrm{m}$ by nitrogen supersaturation at $623 \mathrm{~K}$ for $14.4 \mathrm{ks}$.

\subsection{Grain Size Effect on the Nitrogen Supersaturation}

XRD was employed to describe the nitrogen supersaturation in the nitrided NGSS304 and FGSS304 at $673 \mathrm{~K}$, respectively. Figure 3 compares the XRD diagrams of the NGSS304 and FGSS304 plates before and after plasma nitriding. The as-received, bare NGSS304 is characterized by three high-intensity peaks of $\gamma(111), \gamma(200)$, and $\gamma(220)$ at $2 \theta=43.4^{\circ}$, $50.82^{\circ}$, and $74.5^{\circ}$, respectively. A very small peak at $2 \theta=44.68^{\circ}$ denotes the martensitic phase, transformed by the mechanical polishing for the preparation of specimens. Through the plasma nitriding process, all the austenitic lattices were elastically strained to elongate themselves in the c-axis and to form the expanded austenite $\left(\gamma_{\mathrm{N}}\right)$ or the so-called S-phase $[16,17]$. The original peaks of AISI304 shifted to the lower $2 \theta$, from $43.4^{\circ}$ to $41.1^{\circ}$, from $50.82^{\circ}$ to $47.94^{\circ}$, and from $74.5^{\circ}$ to $70.08^{\circ}$, respectively. These peak shifts from $\gamma$ (111) to $\gamma_{N}(111)$, from $\gamma(200)$ to $\gamma_{N}(200)$, and from $\gamma(220)$ to $\gamma_{N}$ (220), characterize the nitrogen supersaturation in NGSS304. In parallel with these $\gamma_{\mathrm{N}}$ phases, the expanded martensitic peaks were also detected at $2 \theta=43.7^{\circ}$ and $63.5^{\circ}$. This reveals that nitrogen supersaturation by $\gamma \rightarrow \gamma_{\mathrm{N}}$ induces the phase transformation by $\gamma_{\mathrm{N}} \rightarrow \alpha^{\prime}{ }_{\mathrm{N}}$. A negligibly small peak was detected at $2 \theta=37.5^{\circ}$ at trace level, which corresponds to the chromium nitrides. That is, the nitrogen supersaturation inevitably accompanies the elastic lattice stretch in $\gamma$-phase and the transformation from $\gamma_{\mathrm{N}}$ to $\alpha^{\prime}{ }_{\mathrm{N}}$ but without precipitation to nitrides.

Intense rolling was employed to refine the normal grain size of NGSS304 to the fine one of FGSS304. During this rolling, the austenitic phase is transformed to the martensitic phase by shear straining. In fact, three peaks intrinsic to the martensitic phase are detected in Figure 3 besides the intrinsic peaks of $\gamma(111), \gamma(200)$, and $\gamma$ (220) to the original austenite. For example, $\alpha^{\prime}(110), \alpha^{\prime}(200)$, and $\alpha^{\prime}(211)$ peaks are detected at $2 \theta=44.68^{\circ}, 65.08^{\circ}$, and $82.14^{\circ}$, respectively. This implies that the austenitic phase in the NGSS304 makes a nearly full transformation to martensite through this massive compressive straining. After plasma 
nitriding of this rolled AISI304, these martensitic lattices expand by themselves since both $\alpha^{\prime}$ (110) and $\alpha^{\prime}$ (200) peaks shift to the expanded $\alpha^{\prime}{ }_{N}(110)$ and $\alpha^{\prime}{ }_{N}(200)$ as detected at $2 \theta=43.88^{\circ}$ and $63.66^{\circ}$, respectively. In a similar manner, the residual austenite lattices elongate in the c-axis; e.g., the $\gamma(111)$ and $\gamma(220)$ peaks shift to the $\gamma_{N}(111)$ and $\gamma_{N}(220)$, respectively, as reported in [18]. These $\gamma_{\mathrm{N}}$ phases detected are $2 \theta=41.56^{\circ}$ and $70.14^{\circ}$. As noticed in Figure 3, the $2 \theta$ positions in XRD diagrams for $\gamma_{\mathrm{N}}$ and $\alpha^{\prime}{ }_{\mathrm{N}}$ are coincident with each other between the nitrided NGSS304 and FGSS304 specimens. This implies that the nitrogen supersaturation is itself insensitive to the grain size and crystallographic structure at the vicinity of the AISI304 specimen surface.

The effect of holding temperature on the nitrogen supersaturation process was also investigated. Figure 4 depicts the variation of XRD diagrams for the nitrided NGSS304 with a decreasing holding temperature from $693 \mathrm{~K}$ to $623 \mathrm{~K}$. There is no fundamental difference among the four NGSS (N) plates, revealing that nitrogen supersaturation advances in a similar manner irrespective of holding temperatures below $693 \mathrm{~K}$.

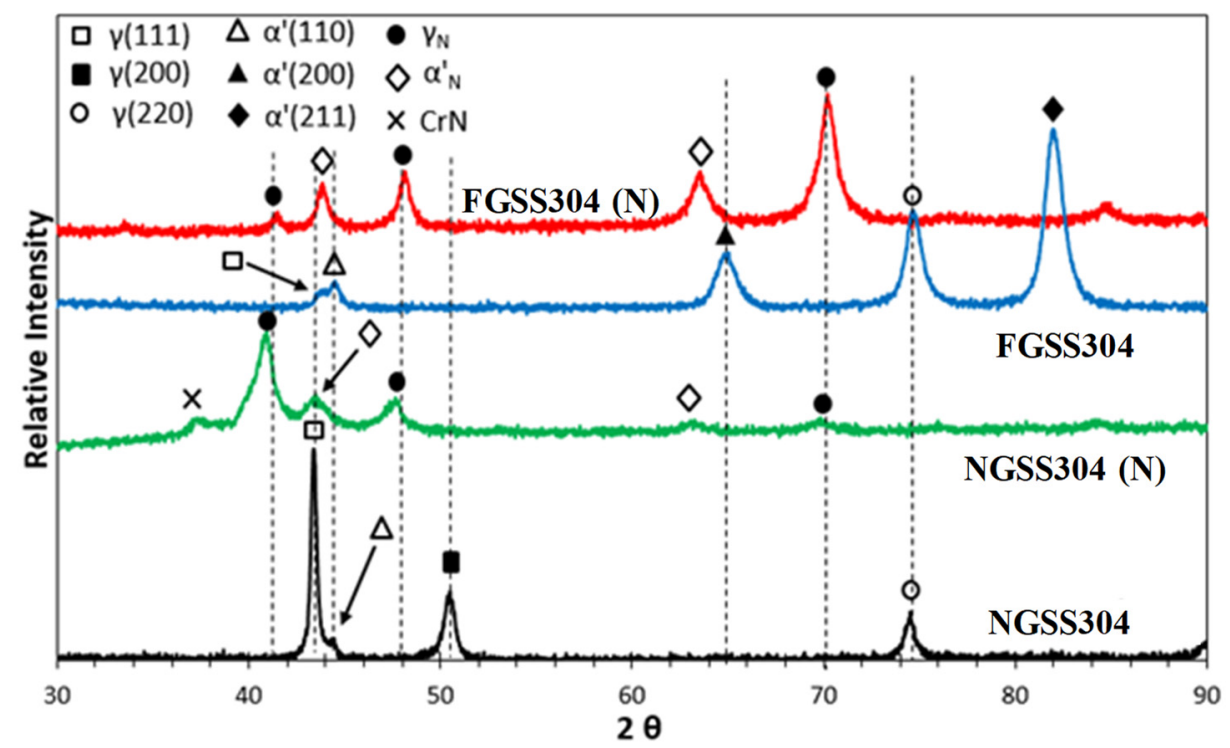

Figure 3. Comparison of the XRD diagrams between NGSS304, FGSS304, and their nitrided NGSS $(\mathrm{N})$ and FGSS304 (N) at $673 \mathrm{~K}$.

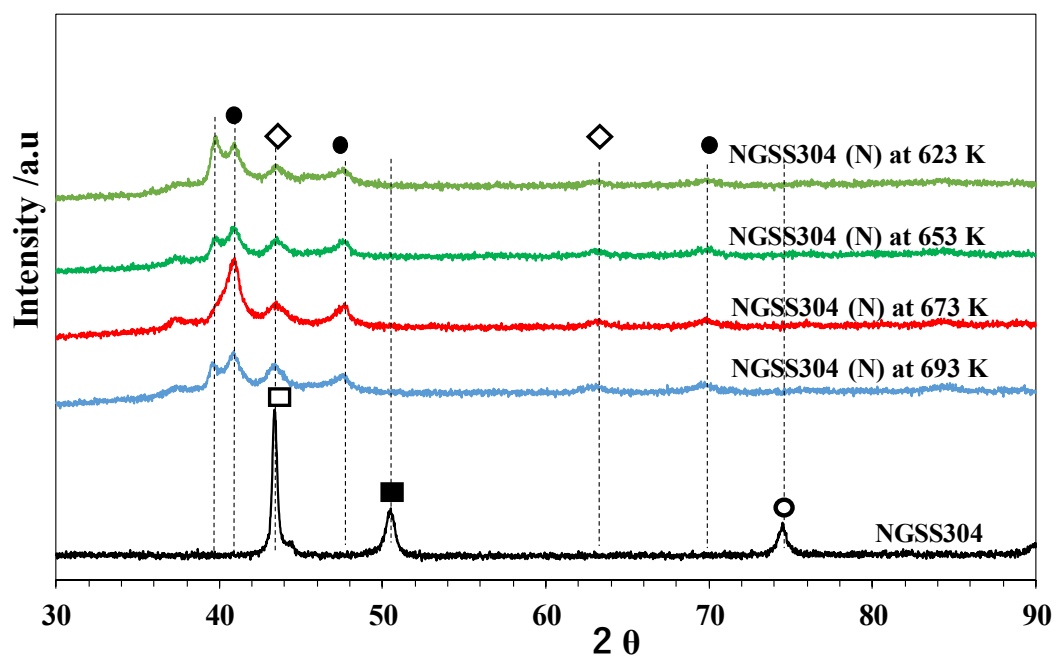

Figure 4. Variation of the XRD diagrams for the nitrided NGSS304 or NGSS304 (N) plates with decreasing the holding temperature from $693 \mathrm{~K}$ to $623 \mathrm{~K}$. 


\subsection{Microstructure of NGSS304 and FGSS304 Plates after Plasma Nitriding at $623 \mathrm{~K}$ for $14.4 \mathrm{ks}$}

The primary effect of grain size on the nitrogen supersaturation process was investigated by SEM-EDS analysis on the cross-section of nitrided NGSS304 and FGSS304 plates at $623 \mathrm{~K}$ for $14.4 \mathrm{ks}$. In addition, EBSD analysis was also employed to describe the crystallographic structure through inverse pole figure (IPF) mapping, the phase transformation by phase mapping, and the plastic straining by kernel angle misorientation (KAM) distribution, respectively. Figure 5 shows the SEM image and nitrogen mapping on the cross-section of NGSS304 (N). The nitrided layer thickness reached $50 \mu \mathrm{m}$ with a surface hardness of $1630 \mathrm{HV}$ and an average hardness of $1300 \mathrm{HV}$ over the nitrided layer. The maximum nitrogen content was $24 \mathrm{at} \%$ at the surface and the average nitrogen content was 16 at $\%$, much higher than the maximum solid solubility of nitrogen by 0.3 at $\%$ at $623 \mathrm{~K}$. At the nitriding front end or a depth of $50 \mu \mathrm{m}$, the hardness approaches the matrix hardness of NGSS304 at $400 \mathrm{HV}$ but the nitrogen content remains 5 at $\%$. This nitrogen content in the depth reaches zero around $70 \mu \mathrm{m}$ from the surface. This non-zero nitrogen content beyond the nitriding front end implies that the nitrogen supersaturation advances heterogeneously even below the nitrided layer.

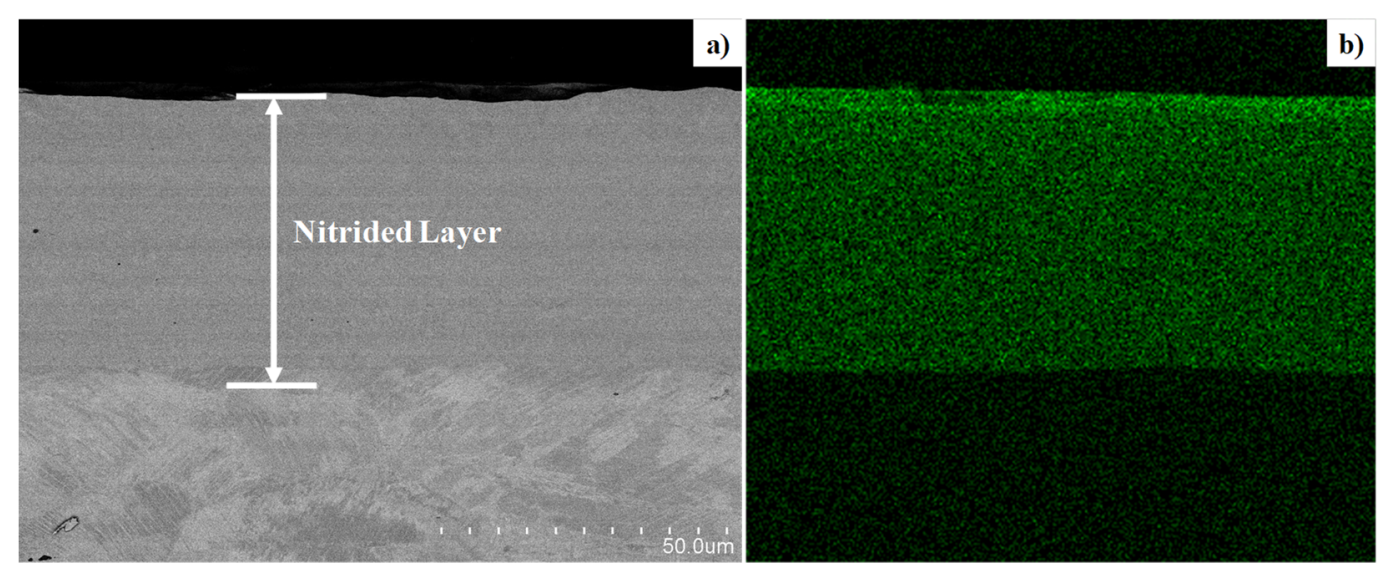

Figure 5. SEM-EDX analysis of the NGSS304 plate after nitriding at $623 \mathrm{~K}$ for $14.4 \mathrm{ks}$. (a) Crosssectional SEM image, and (b) nitrogen mapping from its surface to the depth.

EBSD was a powerful tool to describe the microstructure evolution during plasma nitriding as stated in [9,12-15]. Figure 6a depicts the IPF distribution from the surface to the depth (d) of $130 \mu \mathrm{m}$. The original NGSS304 microstructure, with an average grain size of $15 \mu \mathrm{m}$, is refined to a nano-sized crystalline structure from the surface to $\mathrm{d}=35 \mu \mathrm{m}$. This fine nanostructure abruptly changes to a heterogeneously nitrided zone at a depth of $35 \mu \mathrm{m}$ above the nitriding front end. In agreement with this abrupt nanostructure change, the uniform KAM distribution with maximum angles changes to a heterogeneous state with a mixture of rotated angles in Figure $6 \mathrm{~b}$. The $\gamma_{\mathrm{N}^{-}} \alpha_{\mathrm{N}}^{\prime}$ two-phase nanostructure comes back to a nearly single $\gamma_{\mathrm{N}}$-phase in Figure $6 \mathrm{c}$. As reported in $[14,15,19]$, the nitrogen solute diffuses through the refined grain and zone boundaries in the nitrogen supersaturation. This microstructure change is caused by the autonomous mode change from heterogeneous nitrogen supersaturation to homogeneous nitrogen supersaturation.

Below the nitriding front end in Figure 6, the nitrogen solute diffuses along the zone boundaries, which are shown as the colorfully striped zones in Figure 6a and the highly angled KAM stripes in Figure $6 \mathrm{~b}$. This local nitrogen diffusion by nitrogen supersaturation advances deeper than $\mathrm{d}=70 \mu \mathrm{m}$ where the average nitrogen content $[\mathrm{N}]$ goes to zero. This implies that the homogeneous nitrogen supersaturation from the surface follows the heterogeneous nitrogen supersaturation during the plasma nitriding of NGSS304 at 623 $\mathrm{K}$. This mode change is triggered by the kinematic diffusion path density from its sparse network below $d=35 \mu \mathrm{m}$ in Figure $6 \mathrm{~b}$ to its dense network above $d=35 \mu \mathrm{m}$. This mode change is possibly controlled by the initial grain size. 

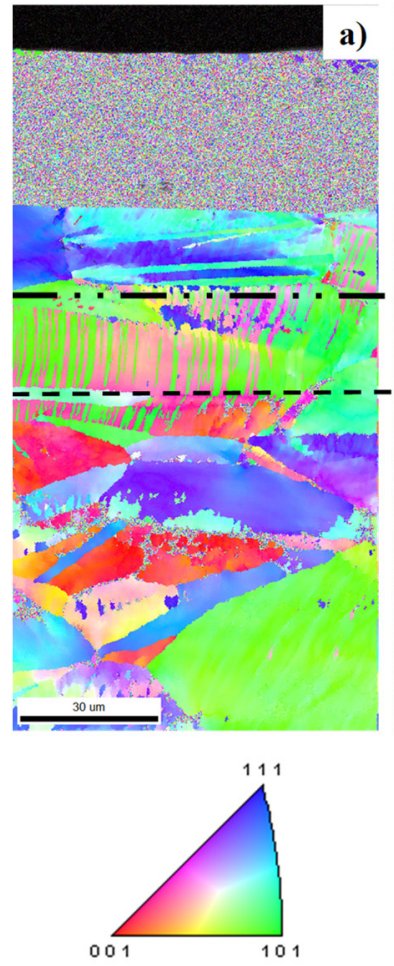
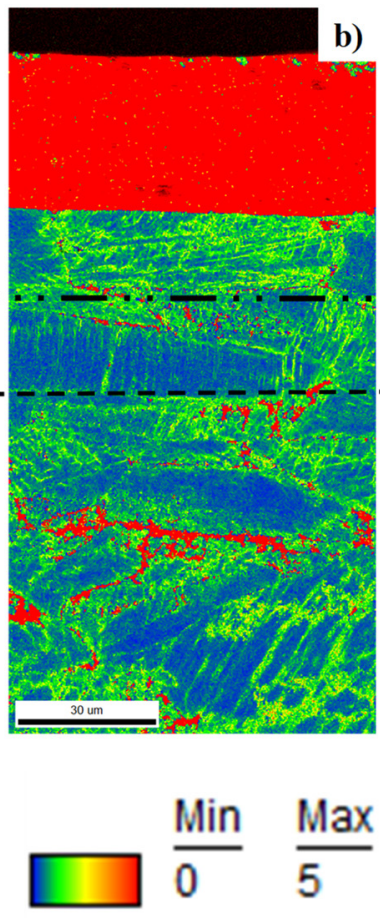

b)

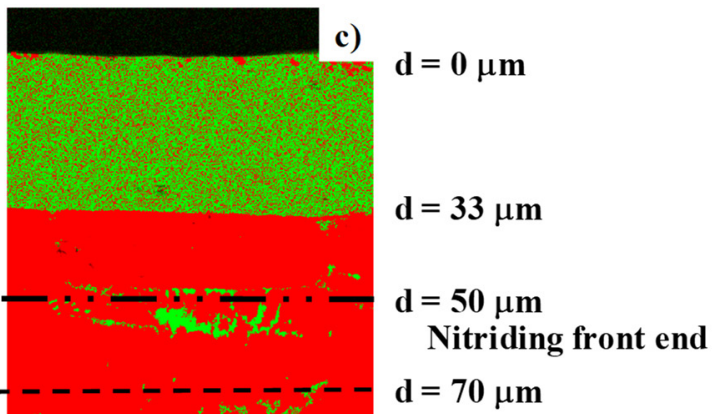

$[\mathrm{N}]$ goes to zero

Figure 6. EBSD analysis of the nitrided NGSS304 plate at $623 \mathrm{~K}$ for $14.4 \mathrm{ks}$. (a) IPF distribution from the surface to the depth, (b) KAM distribution, and (c) phase mapping.

FGSS304 was also nitrided at $623 \mathrm{~K}$ for $14.4 \mathrm{ks}$. As depicted in Figure 7, the homogeneous nitrided layer with a thickness of $60 \mu \mathrm{m}$ was attained with this plasma nitriding. The maximum hardness at the surface was $1350 \mathrm{HV}$ and approached $670 \mathrm{HV}$ at $\mathrm{d}=75 \mu \mathrm{m}$. The maximum nitrogen content was $25 \mathrm{at} \%$, the average content was $15 \mathrm{at} \%$ and approached zero around $\mathrm{d}=75 \mu \mathrm{m}$. In this FGSS $304(\mathrm{~N})$, its depth with non-zero average nitrogen content is equal to the nitrided layer thickness. As shown in Figure 8, no changes in IPF, KAM distributions, or phase mapping are seen. This proves that homogeneous nitrogen supersaturation advances to the nitriding front end without the mode change in the case of plasma nitriding the FGSS304. This difference in the nitrogen supersaturation during the plasma nitriding of NGSS304 and FGSS304 at $623 \mathrm{~K}$ also demonstrates that the grain size has a significant influence on the kinematic network of nitrogen diffusion paths in the nitrogen supersaturation at low temperature.

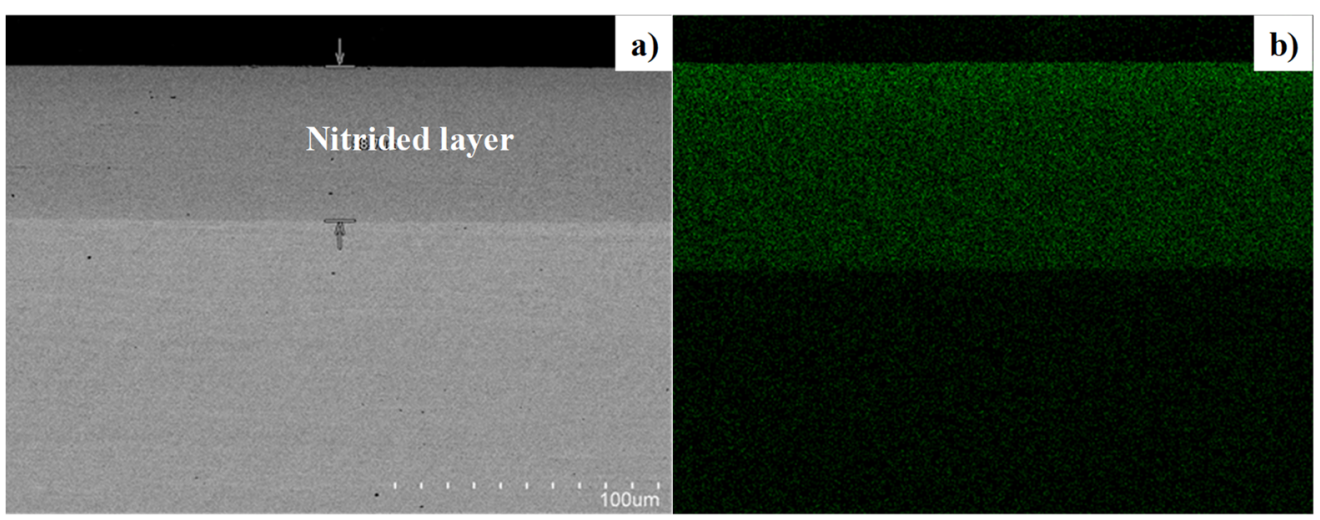

Figure 7. SEM-EDX analysis of the nitrided FGSS304 plate at $623 \mathrm{~K}$ for $14.4 \mathrm{ks}$. (a) SEM image of its cross-section, and (b) nitrogen mapping from the surface to the depth. 


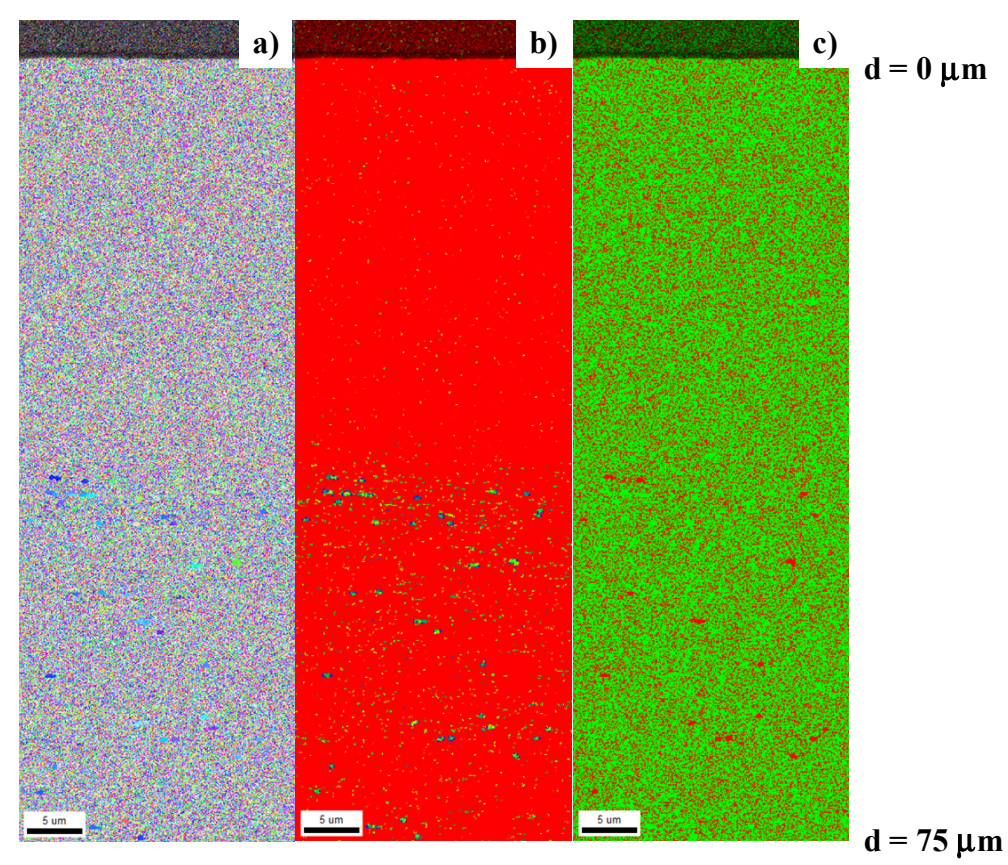

Figure 8. EBSD analysis of the nitrided FGSS304 plate at $623 \mathrm{~K}$ for $14.4 \mathrm{ks}$. (a) IPF distribution from the surface to the depth, (b) KAM distribution, and (c) phase mapping.

\subsection{Nitrogen Supersaturation into Fine-Grained AISI316 Wire}

An FGSS316 wire was nitrided at $623 \mathrm{~K}$ for $14.4 \mathrm{ks}$ using the experimental setup in Figure 2. SEM-EDS was also utilized to describe the microstructure and nitrogen mapping on the lateral and longitudinal cross-sections of plasma nitrided FGSS316 wire together with EBSD analysis.

Figure 9 depicts the SEM image and nitrogen mapping on the lateral and longitudinal cross-sections of nitrided FGSS316 wire. The wire was uniformly nitrided to have a layer thickness of $40 \mu \mathrm{m}$ and the un-nitrided FGSS316 matrix is continuously capped by this nitrided surface layer. Since this nitrided layer thickness is nearly equal to $40 \mu \mathrm{m}$ in the nitrided FGSS316 plates at $623 \mathrm{~K}$ in [12-14], the nitrogen supersaturation process advances from the circumferential surface to the depth of the wire in a similar manner to lowtemperature nitriding in the FGSS304 and FGSS316 plates. The nitrogen supersaturation process was also investigated both in the radial and longitudinal directions of wire.

Figure 10 depicts the KAM distribution as well as the phase mapping on the lateral cross-section. The nitriding front end at $\mathrm{r}=40 \mu \mathrm{m}$ becomes a continuous border between the nitrided layer and the un-nitrided matrix. The nitrided layer for $\mathrm{r}<40 \mu \mathrm{m}$ has high-angled KAM because of the plastic straining by the nitrogen supersaturation. It consists of $\gamma_{N^{-}} \alpha^{\prime}{ }_{N}$ two-phase fine microstructures. This implies that the circumferential surface of the wire is almost homogeneously nitrided to form the two-phase surface layer. However, as also pointed in [14], the expanded austenite regions, which are denoted by "a" in Figure 10, are left in the circumferential direction on the inside of this two-phase nitrided layer. Figure 11 depicts the IPF mapping of the lateral cross-section in the normal (ND), rolling (RD) and tangential directions (TD), respectively, in region A of the nitrided layer and in region B of the wire matrix.

The sheared large grains in the rolled FGSS316 wire are partially nitrided and the retained $\gamma$-phase grains with specified crystallographic orientations are left in the two-phase, super-fine-grained structure of the nitrided layer. As shown by " $b$ " in Figures 9 and 10, the $\alpha^{\prime}$-phase fine grains with the high KAM-angles are formed from the nitriding front end to the internal depth of the original FGSS316 matrix. 


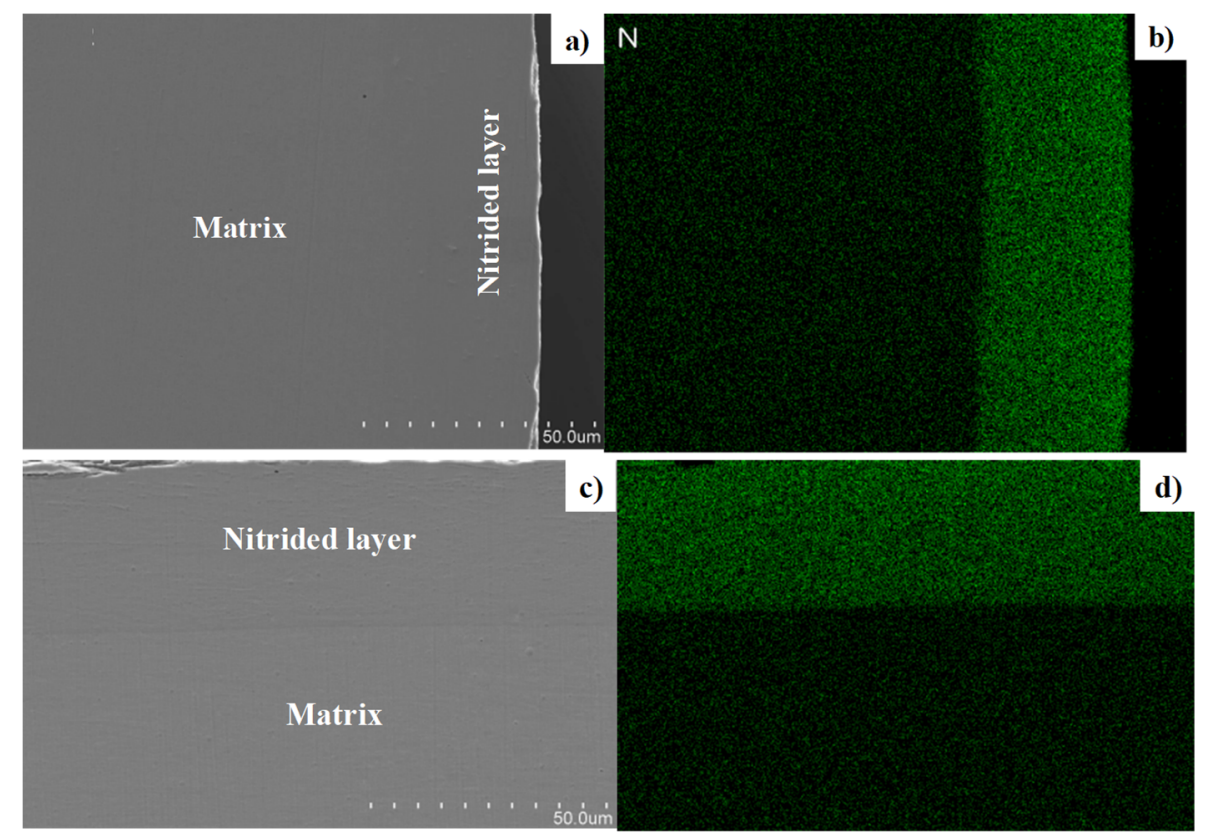

Figure 9. SEM-EDX analysis of the nitrided FGSS316 wire at $623 \mathrm{~K}$ for $14.4 \mathrm{ks}$. (a) SEM image of the lateral cross-section of the nitrided wire, (b) nitrogen mapping of its lateral cross-section, (c) SEM image of its longitudinal cross-section, and (d) nitrogen mapping of its longitudinal cross-section.

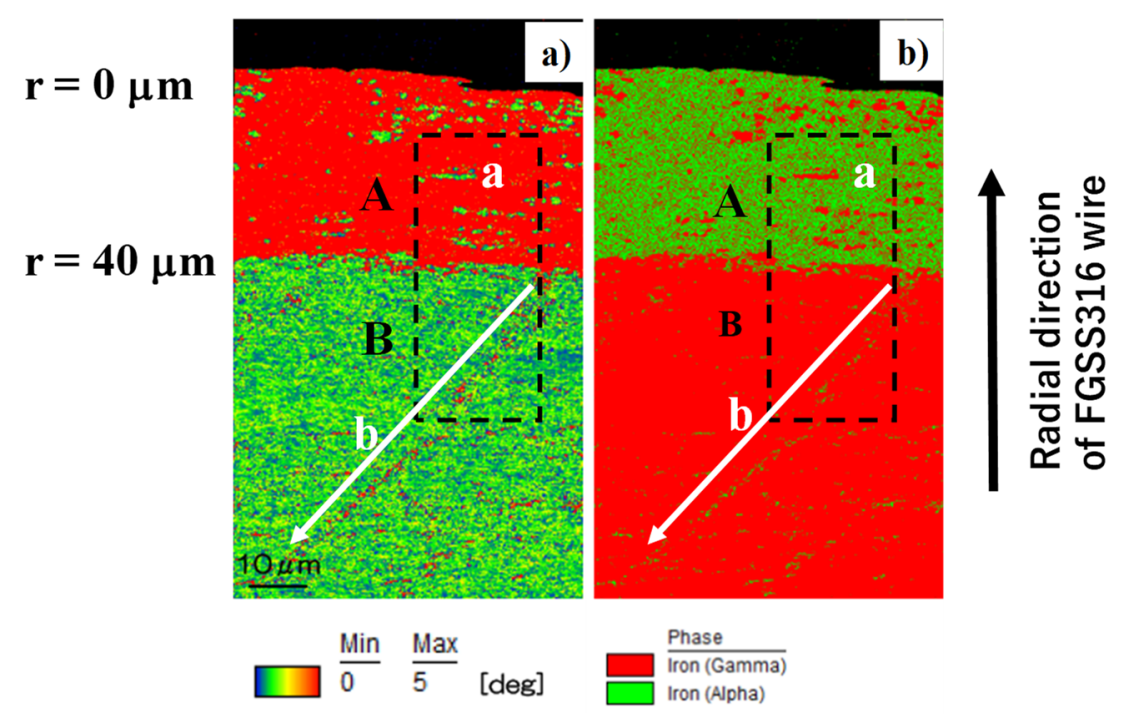

Figure 10. EBSD analysis of the lateral cross-section of nitrided FGSS316 wire at $623 \mathrm{~K}$ for $14.4 \mathrm{ks}$. (a) KAM distribution, and (b) phase mapping. The arrow " $b$ " indicates the plastically strained and $\mathrm{a}^{\prime}$-phase zones from the nitriding front end to the depth in the core matrix of wire.

Figures 12 and 13 depict the KAM distribution, the phase mapping, and the IPF distribution on the longitudinal cross-section. The core of the un-nitrided matrix is uniformly constrained by the ultrafine, two-phase layer. Due to this constraint of the matrix by the nitrided layer, the phase transformation is induced in the core matrix from $\gamma$ - to $\alpha^{\prime}$-phases. Irrespective of this transformation, the core matrix has an equiaxial grain structure as seen in Figure 13. 


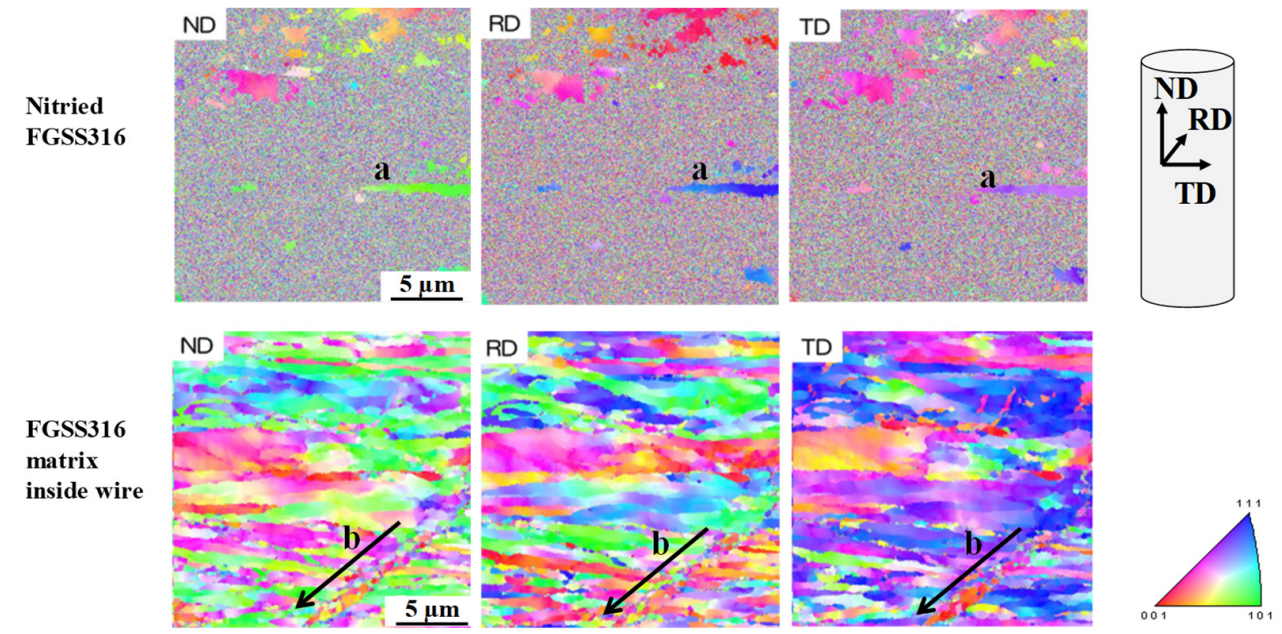

Figure 11. IPF distribution of the lateral cross-section of nitrided FGSS316 layer and matrix inside the wire in the ND (normal direction), RD (rolling direction), and TD (tangential direction). "a" denotes for the retained austenitic grains. The arrow " $b$ " indicates the refined grains in the matrix of wire.
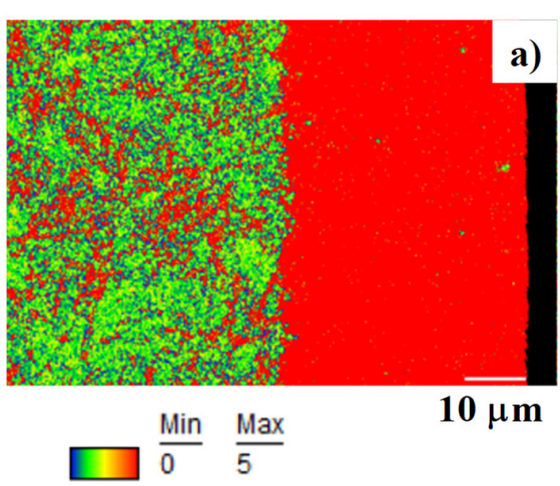

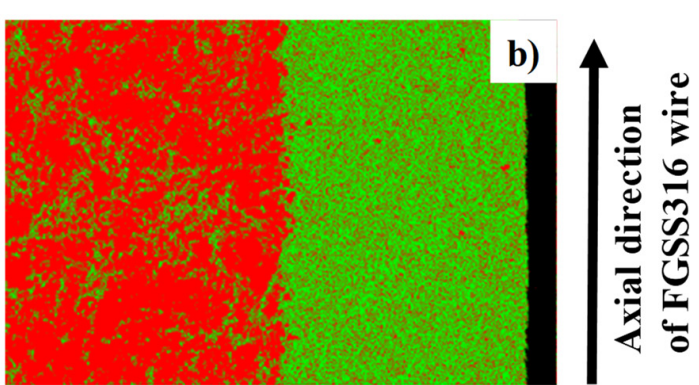

Phase

Iron (Gamma)

Figure 12. EBSD analysis on the longitudinal cross-section of nitrided FGSS316 wire at $623 \mathrm{~K}$ for 14.4 ks. (a) KAM distribution, and (b) phase mapping.

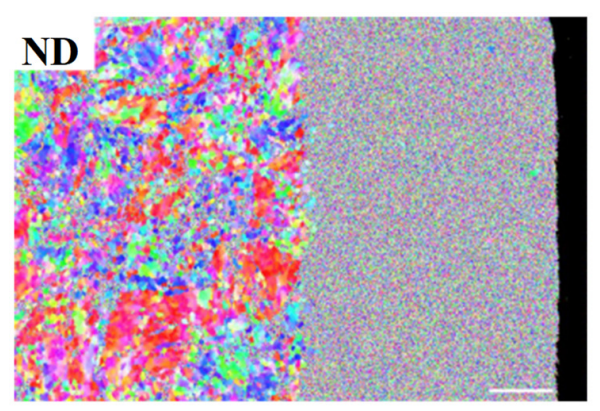

$5 \mu \mathrm{m}$

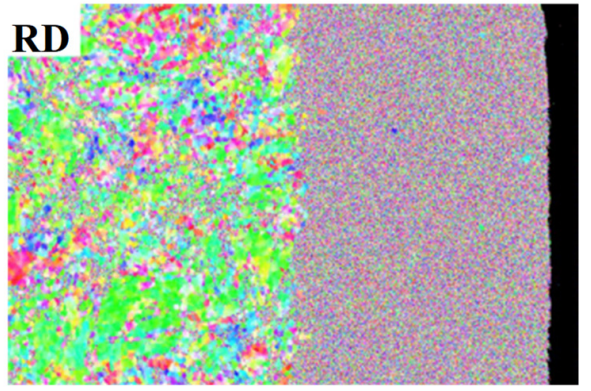

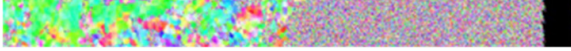
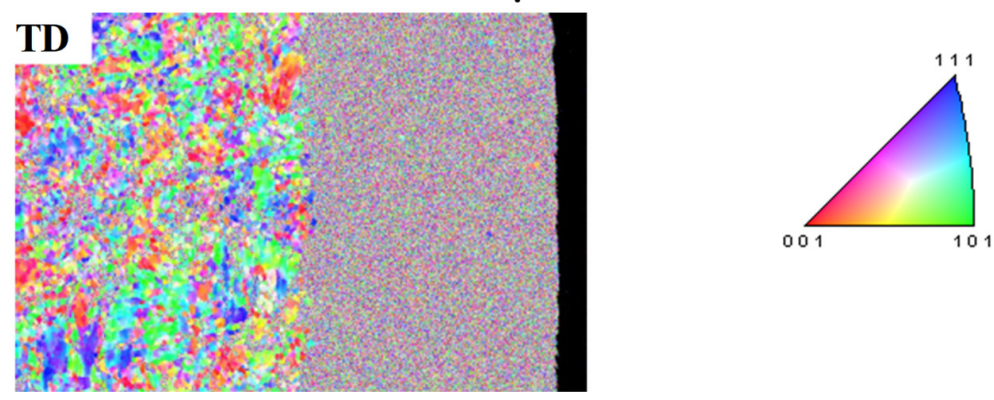

Figure 13. IPF distribution on the longitudinal cross-section of nitrided FGSS316 layer and matrix inside the wire in the ND (normal direction), RD (rolling direction), and TD (tangential direction). 


\subsection{Mechanical Performance of Nitrided AISI316 Wire in Tension}

The nitrided AISI316 wire was uniaxially loaded in tensile to describe its mechanical performance and the effect of stress on the microstructure evolution in loading. The KAM distribution, phase mapping, and IPF profile on the longitudinal cross-section are compared before and after the uniaxial tensile testing.

As depicted in Figure 14, highly angled grains align axially in the tensile direction and the $\alpha^{\prime}$-phase grains are also formed in this axial direction. This implies that equiaxial $\gamma$ and $\alpha^{\prime}$-phase grains in Figure 12 deform by themselves to form the fibrous structure along the tensile direction. Each highly angled zone in Figure 12a forms an $\alpha^{\prime}$-phase fiber. These $\alpha^{\prime}$-fibers are assembled into an $\alpha^{\prime}$-bundle; this $\alpha^{\prime}$-bundle is surrounded by assemblies of $\gamma$-fibers or $\gamma$-bundles. The area fraction of $\alpha^{\prime}$-bundles in this longitudinal cross-section becomes sparse at the vicinity of the nitrided layer and increases with the depth. This suggests that this $\alpha^{\prime}$-bundle has the maximum fraction at the center of the wire matrix just before its fatal ductile fracture.
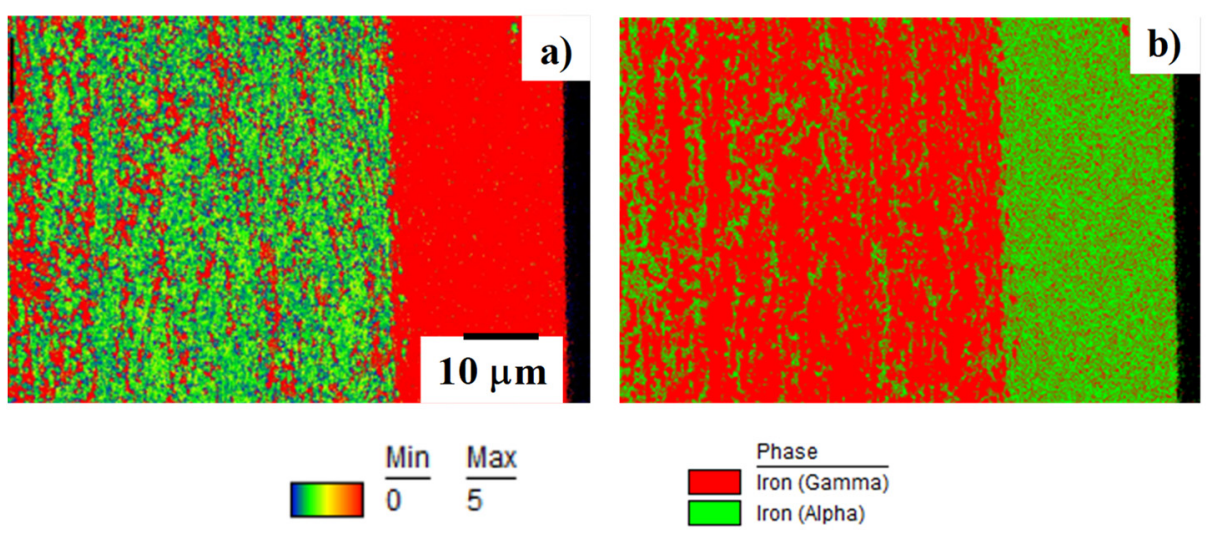

Figure 14. EBSD analysis on the longitudinal cross-section of nitrided FGSS316 wire after uniaxial tensile loading. (a) KAM distribution, and (b) phase mapping.

Figure 15 depicts the crystallographic structure of these $\alpha^{\prime}$ - and $\gamma$-bundles in ND, RD, and TD on the longitudinal cross-section, respectively. Most of the $\alpha^{\prime}$-bundles are aligned to have a crystallographic orientation of (111) in TD. These microstructure observations reveal that the equiaxial austenitic grains with a size of $2 \mu \mathrm{m}$ change to a fine fibrous structure with a fiber diameter of $0.5 \mu \mathrm{m}$, where the martensitic bundles are formed to have the preferred orientation towards the tensile loading direction under the mechanical constraint by the austenitic bundles. Microstructure alignment in the above is induced by uniaxial tensile loading under the constraint of the nitrided layer. The effect of this microstructure change on the mechanical response of the nitrided FGSS316 wire after uniaxial loading was also determined.

Figure 16 compares the hardness profile on the lateral cross-section of nitrided wire before and after loading. The nitrided layer before uniaxial loading has a hardness of $1400 \mathrm{HV}$ in agreement with the reported average hardness of the lateral cross-section of the nitrided FGSS316 plate [14]. This hardness abruptly decreases from $1400 \mathrm{HV}$ to $400 \mathrm{HV}$ at the nitriding front end of $40 \mu \mathrm{m}$; this hardness of $400 \mathrm{HV}$ becomes constant toward the center of the inner matrix. After uniaxial loading, the matrix hardness remains the same as $400 \mathrm{~V}$, while high hardness in the nitrided layer is further enhanced to be $1600 \mathrm{HV}$. This increase of hardness in the nitrided layer by uniaxial loading only corresponds to the microstructure evolution and phase transformation from $\gamma_{\mathrm{N}}$-phase to $\alpha^{\prime}{ }_{\mathrm{N}}$-phase in the nitrided layer as observed in the microstructure change at the nitrided layer from Figures 14 and 15. 

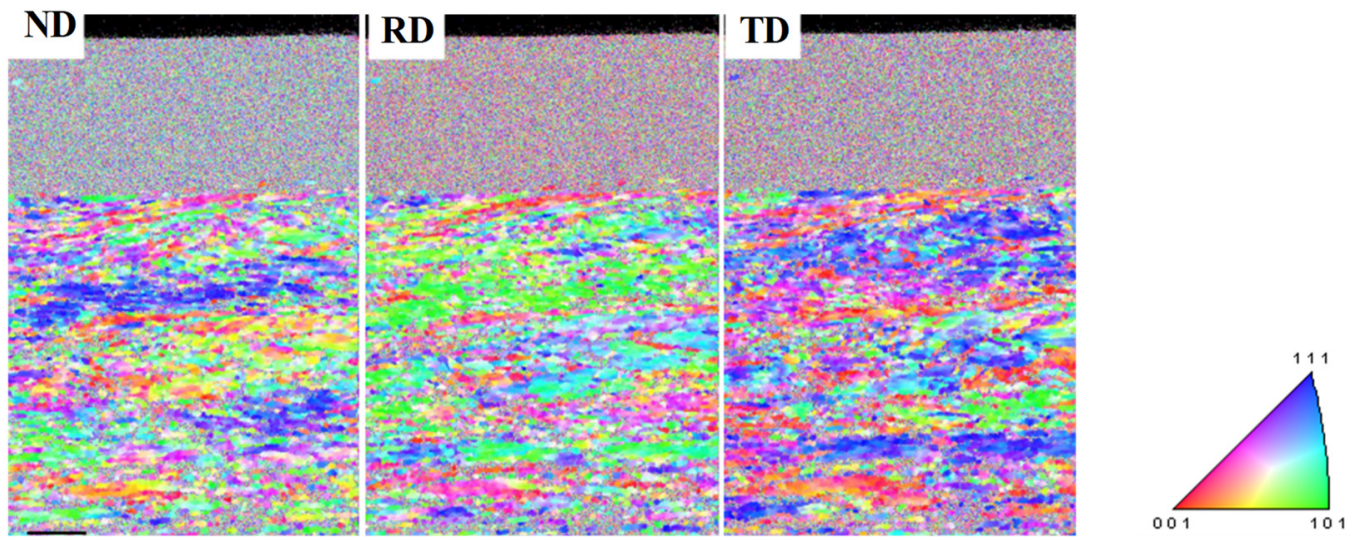

$10 \mu \mathrm{m}$

Figure 15. IPF distribution on the longitudinal cross-section of nitrided FGSS316 wire in the ND, RD, and TD after uniaxial tensile loading.

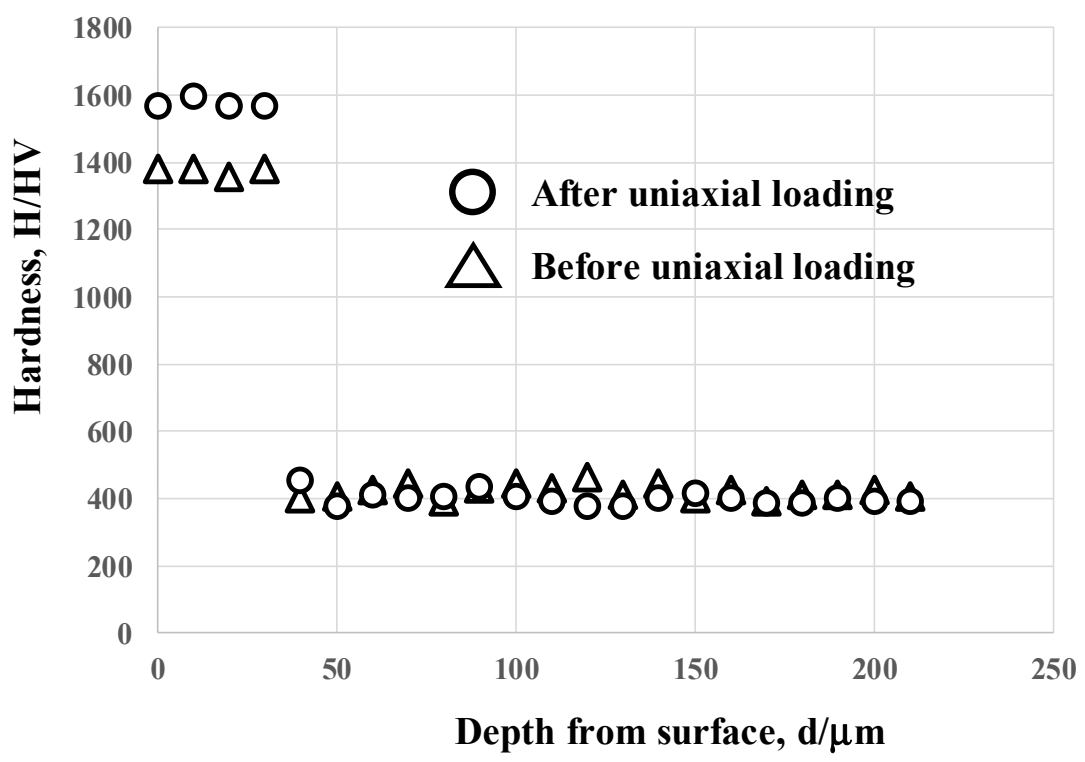

Figure 16. Hardness distribution on the longitudinal cross-section of nitrided FGSS316 wire before and after the uniaxial tensile loading.

The uniaxially applied stress $\left(\sigma_{\text {app }}\right)$ to stroke $(\delta)$ relationship is compared between the bare and nitrided FGSS316 wires in Figure 17. The stiffness $(\mathrm{K})$ is defined as the average change of the applied stress to the measured stroke up to $\delta=1 \mathrm{~mm}$; e.g., $\mathrm{K}=\sigma_{\mathrm{app}} / \delta$. In the original FGSS316 wire, its stiffness becomes $\mathrm{K}_{0}=500 \mathrm{MPa} / \mathrm{mm}$ before nitriding; while the nitrided FGSS316 wire has a slightly greater stiffness $\left(K_{N}\right)$ than $K_{0}$; e.g., $K_{N}=580 \mathrm{MPa} / \mathrm{mm}$. The present nitrided wire is presumed as a composite of the nitrided layer with stiffness $K_{1}$ and the FGSS316 matrix with $K_{0}$. After the rule of thumb for the stiffness of composite materials [20], $\mathrm{K}_{\mathrm{N}}$ is simply estimated by $\mathrm{K}_{\mathrm{N}}=(1-\mathrm{f}) \times \mathrm{K}_{0}+\mathrm{f} \times \mathrm{K}_{1}$, where $\mathrm{f}$ is the area fraction of the nitrided layer on the cross-section of the wire. In the present case, this $f$ is only $6 \%$ because of the nitrided layer thickness of $40 \mu \mathrm{m}$ of the wire lateral cross-section with a diameter of $2.6 \mathrm{~mm}$. Assuming that $\mathrm{K}_{1}=(1600 \mathrm{HV} / 400 \mathrm{HV}) \times \mathrm{K}_{0}, \mathrm{~K}_{\mathrm{N}}=1.19$ $\times$ K0 590 MPa. This implies that the FGSS316 matrix in the nitrided wire is elastically constrained by the nitrided surface layer with higher hardness and stiffness similar to the lateral composite material. 


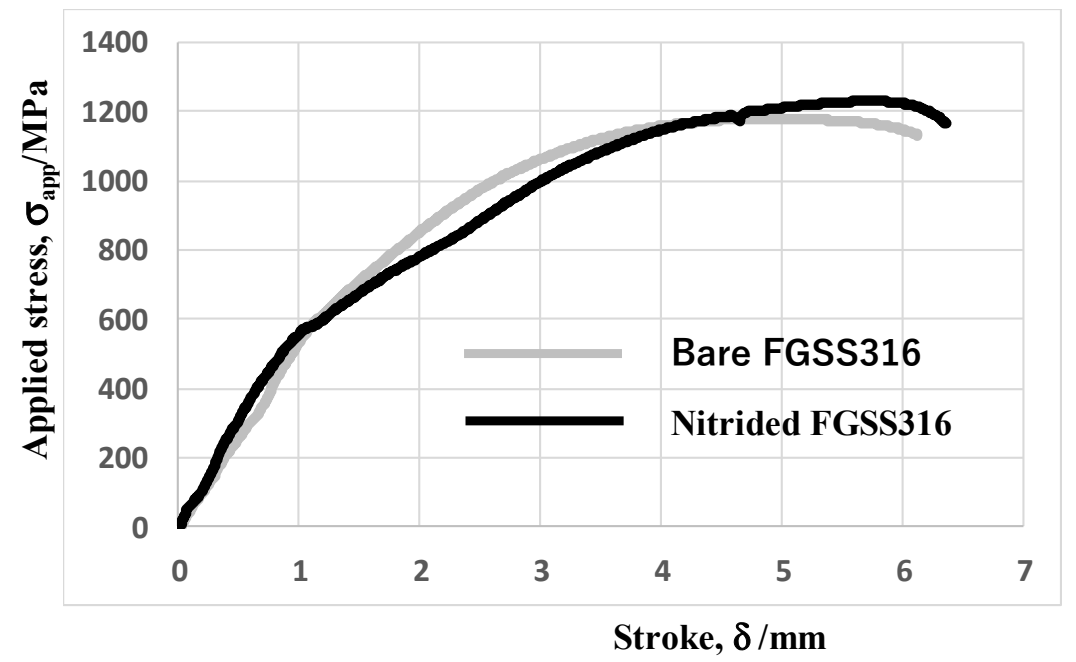

Figure 17. Comparison of the applied stress to stroke relationship between bare and nitrided FGSS316 wires in the uniaxial tensile loading.

In the elastoplastic regime of $\sigma_{\text {app }}-\delta$ relations in Figure 17, the work-hardening process is enhanced in the nitrided wire to attain higher ultimate stress $\left(\sigma_{U}\right) ;$ e.g., $\sigma_{U}=1.23 \mathrm{GPa}$ in the nitrided FGSS316 wire at $\delta=5.7 \mathrm{~mm}$ or at the nominal strain $(\varepsilon)$ of 0.19 while $\sigma_{U}=1.18 \mathrm{GPa}$ in the bare FGSS316 one at $\delta=4.9 \mathrm{~mm}$ or $\varepsilon=0.17$. Higher maximum strength and more uniform elongation in the above also implies that non-proportional elastoplastic straining is retarded in the uniaxial loading and that work hardening is stabilized by the circumferential constraint in the presence of a two-phase fine-grained nitrided layer.

\section{Discussion}

In the low-temperature plasma nitriding of austenitic stainless steels, the homogeneous nitrogen supersaturation process follows the heterogeneous nitrogen supersaturation process. This change of nitrogen supersaturation process is governed by the nitrogen diffusion network through the newly formed fine-grain and zone boundaries. When the network density is sparse, the nitrogen supersaturation locally advances into the depth of the network; while this process becomes homogeneous under high network density. Hence, this kinematic relationship between the nitrogen diffusion networks reflects the nitrogen supersaturation process as a grain size effect. With the refinement of the initial grain size in the austenitic stainless steels, every inner nitriding step becomes homogeneous to form a uniform nitrided layer as an ultrafine-grained, two-phase microstructure. The nitriding front end becomes a border between the nitrided layer and the un-nitrided matrix. This initial grain effect on the nitrogen supersaturation is noticed both in the nitrided plates and wires at $623 \mathrm{~K}$.

When using the fine-grained stainless steel wires, the nitrided layer at $623 \mathrm{~K}$ for $14,4 \mathrm{ks}$ has a uniform, ultrafine-grained two-phase layer with a thickness of $40 \mu \mathrm{m}$ and a hardness of $1400 \mathrm{HV}$ to cover the core matrix at a hardness of $400 \mathrm{HV}$. Under this constraint, the nitrided wire had higher stiffness, ultimate strength, and elongation than the bare, unnitrided one. This improvement of mechanical performance is preferable to biomedical tools such as a guide wire and surgery wire in endoscope operations. In particular, the $\gamma_{\mathrm{N}^{-}}$ $/ \alpha^{\prime}{ }_{N}$-phase ultrafine structure of the nitrided layer also improves the wear and corrosion toughness of these guide wires compared to bare rolled austenitic stainless steel wires with a high volume fraction of martensite.

The core matrix of FGSS316 wire changes its microstructure from an equiaxial state to a fibrous state during the uniform tensile loading at RT. In particular, as seen in Figures 14 and 15, the work hardening austenitic fibrous bundles coexist with the neighboring martensitic ones even before the fatal break-away of the composite wire. The fraction 
of martensitic bundles in the core matrix increases around the center of the wire core while it is sparse in the vicinity of a skin nitrided layer. Hence, the fatal cracking is considered to gradually occur from the break-away at the center of the wire. This retardation of fatal cracking is also preferable to surgery wires. Increases in the hardness of the skin nitrided layer suggest that the structural integrity of a biomedical wire could be enhanced by a prestraining effect. In particular, the increase of wire stiffness by this prestraining proves the high mechanical response as a guide wire in surgery operation.

\section{Conclusions}

Two types of AISI304 specimen with average grain sizes of $15 \mu \mathrm{m}$ and $2 \mu \mathrm{m}$, are plasma nitrided to describe the effect of grain size and holding temperature on the inner nitriding behavior. Little fundamental difference is noticed in the nitrided crystalline structure at the surface, even when varying the grain size or the holding temperature from $693 \mathrm{~K}$ to $623 \mathrm{~K}$. Nitrogen supersaturation into the original $\gamma$ - and $\alpha^{\prime}$-AISI304 matrices is common to those specimens together with a refinement of grain size down to $0.1 \mu \mathrm{m}$, large plastic straining, and $\gamma_{\mathrm{N}} / \alpha^{\prime}{ }_{\mathrm{N}}$ two-phase structuring. A fundamental difference is recognized in the nitrogen supersaturation process into the depth of the matrix. The heterogeneous nitrogen supersaturation becomes homogeneous when nitriding the NGSS304. This mode change in nitriding occurs when the local nitrogen diffusion network density becomes dense enough to sustain the uniform nitriding steps. When using FGSS304, this high network density is preserved during inner nitriding so that no heterogeneous nitrogen supersaturation process is observed on the cross-section of nitrided FGSS304. This grain size effect on the nitriding behavior proves that the kinematic relationship between the nitrogen diffusion networks has an influence on the low-temperature nitrogen supersaturation process.

The nitrided fine-grain AISI316 wire with a radius of $1.3 \mathrm{~mm}$ has a core structure, where the original FGSS316 matrix is bound by the nitrided layer. This layer consists of two $\gamma_{N^{-}} / \alpha^{\prime}{ }_{N^{-}}$phase microstructure with the average grains size less than $0.1 \mu \mathrm{m}$ down to the nitriding front end of $40 \mu \mathrm{m}$. In the core-structured wire, the FGSS316 core matrix with the hardness of $400 \mathrm{HV}$ is uniformly capped by the nitrided layer with the hardness of $1400 \mathrm{HV}$. During the uniaxial loading, this equi-axis, $\gamma$-phase core structure with a small fraction of $\alpha^{\prime}$-phase is modified to be a composite structure where the fibrous $\gamma$ - and $\alpha^{\prime}$ bundles are axially aligned in the loading direction. The martensitic fiber in these bundles is largely formed by austenitic fiber through the strain-induced phase transformation. This microstructure evolution in the wire core matrix has a significant influence on its mechanical properties. In addition, the hardness of the nitrided layer capping this core matrix is also increased uniformly by $200 \mathrm{HV}$ from $1400 \mathrm{HV}$ to $1600 \mathrm{HV}$ by this uniaxial loading.

This uniaxially tensile loading effect on the mechanical performance and microstructure evolution proved that prestraining of the plasma nitrided FGSS316 wire is effective to control the mechanical properties of composite wires as a surgery wire and a guild wire in biomedical applications. The demand for higher strength and greater elongation in medical wires can be satisfied by this post-loading of nitrided GGSS316 wires.

Author Contributions: Conceptualization, A.F. and T.A.; methodology, A.F. and T.Y.; validation, A.F., T.A., T.Y.; formal analysis, A.F. and T.Y.; investigation, A.F., T.A., and T.Y.; writing—original draft preparation, A.F., T.A.; writing-review and editing, T.A. All authors have read and agreed to the published version of the manuscript.

Funding: This research was financially supported in part by Abe-Initiative, Japan Government.

Institutional Review Board Statement: Not applicable.

Informed Consent Statement: Not applicable.

Data Availability Statement: The data presented in this study are available on request from the corresponding author

Acknowledgments: The authors would like to express their gratitude to T. Komatsu (Komatsu-Seiki Kosakusho, Co., Ltd.) for his help in experiments and discussion. 
Conflicts of Interest: The authors declare no conflict of interest.

\section{References}

1. Niinomi, M.; Narushima, T.; Nakai, M. Advances in Metallic Biomaterials; Springer: Berlin/Heidelberg, Germany, 2015.

2. Berci, G.; Forde, K.A. History of endoscopy. Surg. Endosc. 2000, 14, 5-15. [CrossRef] [PubMed]

3. Aizawa, T.; Shiratori, T.; Komatsu, T. Integrated manufacturing of fine-grained stainless steels for industries and medicals. In Engineering Steels and High Entropy-Alloys; InTechOpen: London, UK, 2019; pp. 1-23.

4. Kukreja, P.; Mangla, M.; Rajput, L.; Anand, K.R.; Kumar, S.; Agarwal, H. Effect of pre-Stretching of surgical stainless steel wires on their ultimate load bearing strength-A prospective study. J. Dent. Spec. 2016, 4, 36-38. [CrossRef]

5. Lipscomb, I.P.; Pinchin, H.E.; Collin, R.; Harris, K.; Keevil, C.W. Are surgical stainless steel wires used for intracranial implantation of PrPSC a good model of iatrogenic transmission from contaminates surgical stainless steel instruments after cleaning? J. Hosp. Infect. 2006, 64, 339-343. [CrossRef] [PubMed]

6. Bhadeshia, H.; Honeycombe, R. Steels: Microstructure and Properties, 3rd ed.; Elsevier: Amsterdam, The Netherlands, 2006.

7. Tomizawa, Y.; Hanawa, T.; Kuroda, D.; Nishida, H.; Endo, M. Corrosion of stainless steel sternal wire after long-term implantation. J. Artif. Organs 2006, 9, 61-66. [CrossRef] [PubMed]

8. Padilha, A.F.; Plaut, R.L.; Rios, P.R. Stainless steel heat treatment. In Stainless Steels; ASM International: Almel, The Netherlands, 2007; pp. 695-735.

9. Aizawa, T. Low temperature plasma nitriding of austenitic stainless steels. In Stainless Steels; InTechOpen: London, UK, 2019; pp. 31-50.

10. Talha, M.; Behera, C.K.; Sinha, O.P. A review on nickel-free nitrogen containing austenitic stainless steels for biomedical applications. Mater. Sci. Eng. C 2013, 33, 3563-3575. [CrossRef] [PubMed]

11. Aizawa, T. Characterization on the properties of nitrided layer in dies and molds: Low temperature plasma nitrided stainless steels. Bull. JSTP 2019, 2, 411-415.

12. Aizawa, T.; Yoshihara, S.-I. Homogeneous and heterogeneous micro-structuring of austenitic stainless steels by the low temperature plasma nitriding. IOP Conf. Ser. Mater. Sci. Eng. 2018, 372, 012049. [CrossRef]

13. Aizawa, T.; Yoshihara, S.-I. Inner Nitriding Behavior and Mechanism in Stainless Steels Type AISI316 at 623 K, 13 th ed.; OS06; SEATUC Symposium: Hanoi, Vietnam, 2019; pp. 13-18.

14. Aizawa, T.; Yoshino, T.; Shiratori, T.; Yoshihara, S.-I. Grain size effect on the nitrogen supersaturation process into AISI316 at 623 K. ISIJ Int. 2019, 59, 1886-1892. [CrossRef]

15. Aizawa, T.; Yoshihara, S.-I. Inner nitriding behavior and mechanism in stainless steels at $753 \mathrm{~K}$ and $623 \mathrm{~K}$. SJSE 2019, 1, 13-20.

16. Bell, T. Surface engineering of austenitic stainless steel. Surf. Eng. 2002, 18, 415-422. [CrossRef]

17. Dong, H. S-phase surface engineering of Fe-Cr, Co-Cr and Ni-Cr alloys. Int. Mater. Rev. 2011, 55, 65-98. [CrossRef]

18. Borgioli, F.; Galvanetto, E.; Bacco, T. Low temperature nitriding of AISI300 and 200 series austenitic stainless steels. Vacuum 2016, 12, 51-60. [CrossRef]

19. Aizawa, T.; Yoshino, T. Plastic Straining for Microstructure Refinement in Stainless Steels by Low Temperature Plasma Nitriding, 12th ed.; OS06; SEATUC Symposium: Yag-Yagarta, Indonesia, 2018; pp. 1-8.

20. Nemat-Nasser, S.; Hori, M. Micromechanics: Overall Properties of Heterogeneous Materials; North-Holland: Amsterdam, The Netherlands, 1992; p. 113. 